\title{
OS AVANÇOS E DESAFIOS DA POLÍTICA DE DESENVOLVIMENTO REGIONAL E NOVAS POSSIBILIDADES DE INTERCÂMBIO COM A UNIÃO EUROPEIA
}

\author{
Henrique Villa da Costa Ferreira ${ }^{1}$
}

\begin{abstract}
Resumo
O artigo trata dos avanços da Política Nacional de Desenvolvimento Regional (PNDR) vislumbrando as possibilidades para o futuro, bem como das possibilidades de cooperação com a União Europeia, mais especificamente com o Departamento-Geral de Política Regional da UE. Informa o artigo que o período pós-2010 coloca desafios importantes para a política regional brasileira como: a) tornar a PNDR uma política de Estado; b) implementar o processo de descentralização da Política, visando modificar o processo de gestão da PNDR, através da criação do Fundo Nacional de Desenvolvimento Regional (FNDR) com a previsão de criação dos Fundos Estaduais de Desenvolvimento Regional; c) alterar o modelo de gestão, uma proposta que envolve múltiplos atores e novas instâncias participativas. Por fim, dentre outros aspectos relativos à cooperação com o Departamento-Geral de Política Regional da União Europeia em curso, o artigo destaca que cabe ao Brasil um papel de líder da cooperação no continente, pois crê que a América do Sul se fragiliza sem ações concretas de integração regional.

Palavras-chave: Política Nacional de Desenvolvimento Regional. Novo Desafio para a Política Regional Brasileira. Cooperação com a União Europeia.
\end{abstract}

\section{Abstract}

The article discusses the advances of the National Policy of Regional Development (PNDR) envisioning the possibilities for the future and the possibilities for cooperation with the European Union, more specifically with the Department General of Regional Policy. The paper states that the post-2010 period poses important challenges for regional policy in Brazil: a) transform the PNDR into a State policy b) implement the process of decentralization of the policy, seeking to modify the process of managing the PNDR by the creation of the National Development Fund (FNDR) with the forecast of creation of the States Funds for Regional Development, c) change the management model, a proposal that involves multiple actors and new participatory models. Finally, among other aspects relating to cooperation with the Department General of Regional Policy of the European Union under way, the paper stresses that it is up to Brazil a leadership in the role of cooperation in the continent, as he believes that South America is weakened without concrete regional integration actions.

Keywords: National Policy for Regional Development. New Challenge for the Brazilian Regional Policy. Cooperation with the European Union.

\footnotetext{
${ }^{1}$ Graduado em Administração pelo Centro Universitário do Distrito Federal, Mestrado em Administração pela Universidade de Brasília e Doutorado em Sociologia pela UnB (1999). Secretário de Políticas de Desenvolvimento Regional do Ministério da Integração Nacional no Governo Lula. http://www.integracao.gov.br/ Email: henrique.ferreira@integracao.gov.br
} 
Em primeiro lugar, devo agradecer o convite da Universidade através do Programa de Pós-Graduação em Geografia e do Programa Desenvolvimento Urbano e Regional, por meio do professor Aldomar Rückert. Gostaria de dizer que é um grande prazer estar aqui participando desse Seminário. Creio que seja uma ótima oportunidade de manter contato com quem está efetivamente produzindo um olhar para o futuro da questão regional do Brasil. Em segundo lugar, porque me possibilita uma oportunidade concreta de me afastar momentaneamente dos conflitos do dia a dia, da burocracia diária e discutir o tema que me apaixona com pessoas qualificadas e um ambiente agradável e instigador.

Acredito que a sequência aqui proposta foi bem interessante, pois a professora Maria Alice Lahorgue colocou com propriedade o pano de fundo da questão regional com contribuições importantes da academia, evidentemente que poderiam ser acrescentados com outras referências como Celso Furtado, Tânia Bacelar de Araújo, Clélio Campolina Diniz, Carlos Azzoni, Wilson Cano, dentre outros. A professora Clarisse Didelon, por sua vez, nos traz a experiência da União Européia, que é muito importante considerar para se fazer um contraponto com a nossa própria política regional.

Minha proposta aqui é falar rapidamente sobre os avanços da Política Nacional de Desenvolvimento Regional (PNDR), sempre vislumbrando as possibilidades para o futuro e, na medida do possível, dialogar com o processo ocorrido no caso europeu. Vou concluir minha participação falando das possibilidades de cooperação com a União Europeia - EU -, mais especificamente com o Departamento-Geral de Política Regional da UE.

Inicialmente, gostaria de lembrar a pesquisa, realizada recentemente, no âmbito do Conselho de Desenvolvimento Econômico e Social (CDES) da Presidência da República, que reúne expressivos representantes de vários setores da sociedade brasileira. Fazem parte desse fórum intelectuais, empresários, ministros, governadores, trabalhadores e formadores de opinião de várias instituições. Nessa pesquisa, 75\% dos entrevistados apontaram as desigualdades regionais como o principal problema brasileiro. Isso demonstra a dimensão do desafio que temos no país e a complexidade da chamada questão regional, porque não faz nenhum sentido, em nenhum lugar do mundo, conviver com tantas diferenças territoriais como as que temos aqui. Isso se deve a muitos fatores, dentre eles a dívida histórica que construímos com boa parte dos territórios brasileiros, forjada no processo desequilibrado e territorialmente concentrado de desenvolvimento do país.

Trazendo à nossa reflexão o caso da UE, pode-se afirmar que o "alargamento" da União Europeia vem proporcionando a incorporação da diversidade ao bloco, mas, por outro lado, gera muitos problemas e coloca muita pressão na política regional europeia. A professora Clarisse Didelon, ontem, falou que existe uma resistência dos países que financiam a política regional em continuar com o processo em andamento. Isso porque os países do Leste Europeu, que ingressaram tardiamente no bloco, possuem muitos problemas estruturais em comparação com os demais países europeus. Para atendimento a tal demanda, são necessários muitos recursos, de toda sorte, ao encontro do que foi realizado no caso de países como Portugal e Espanha, que não são fundadores do mercado comum. Mas o processo não é trivial, não ocorre sem pressão e questionamentos. Recentemente, por ocasião de nossa 
participação no evento que ocorre anualmente em Bruxelas, denominado Open Days 2010 -, o qual reúne os principais atores europeus de cidades e regiões dos estados-membros, para discutir políticas regionais, constatamos que existe muita pressão sobre a estratégia e a próxima fase da política regional europeia.

Voltando ao caso brasileiro, alguns novos elementos estão inseridos na proposta da PNDR, como, por exemplo, o olhar positivo à diversidade regional como aliada à política regional. Da mesma forma, durante muito tempo a política regional brasileira teve um olhar somente para a escala macrorregional, como se o problema regional brasileiro estivesse restrito às Regiões Nordeste, Norte e Centro-Oeste. Isso nos remete à gênese da discussão da questão regional e à contribuição do professor Celso Furtado que, na década de 1950, introduziu a temática na agenda de prioridades do Estado brasileiro, com objetivo de evidenciar as diferenças e diminuir as distâncias que separavam o Norte e do Sul do Brasil (o "Norte" de Furtado incorporava, de certa forma, as três grandes regiões citadas anteriormente).

Pois bem, a PNDR propõe a discussão de alguns temas que já vêm sendo trabalhados na União Europeia. O primeiro deles é que a escala macrorregional não dá mais conta de enfrentar o problema das desigualdades regionais brasileiras. Não por acaso, uma das premissas da Política é a abordagem em múltiplas escalas geográficas, pois os problemas são muito diferentes dentro de cada uma das regiões e, como tal, requerem soluções específicas, detalhadas, para cada contexto regional. Não existe a oposição do Norte versus o Sul, já que temos, no Brasil, vários "Nortes", vários "Nordestes" e várias "Amazônias". O Brasil é um país absurdamente desigual, pois, apesar de sermos uma das dez maiores economias do mundo, ainda somos um dos países que apresentam as maiores desigualdades, como se pode facilmente observar analisando os indicadores econômicos e sociais que medem desigualdades sob qualquer ponto de vista.

A perpetuação das desigualdades regionais brasileiras não faz nenhum sentido. Seja pelo resgate da dívida histórica que temos com territórios excluídos da dinâmica produtiva brasileira, seja pelo contrassenso do ponto de vista econômico, uma vez que tais regiões podem ser geradoras de oportunidades diversas, inclusive para a reprodução agressiva do capital. Entretanto, é mister considerar que o capital não se reproduz da forma ideal onde não existe infraestrutura, por exemplo. Prover infraestrutura, conectividade, capital humano e preparar condições de protagonismo ao encontro do fortalecimento do capital social é dever do Estado. Se o Estado assim não o fizer, ninguém o fará. Nesse caso, o Estado é insubstituível, o que significa dizer que sem tal ação do ente estatal, regiões continuarão excluídas, pois não serão os donos de capital ou outros agentes privados que promoverão tais condições.

É importante destacar que para se modificar a realidade regional marcada por desigualdades, por meio de políticas públicas, sobretudo em casos de políticas de longa maturação e transversais, como as de desenvolvimento regional, as ações propostas requerem grande capacidade de gestão, articulação e integração. Nesse sentido, do ponto de vista 
institucional, a cultura setorial e a descontinuidade das políticas públicas em geral que ainda nos caracterizam são óbices à redução das desigualdades regionais brasileiras. Creio que o Ministério da Integração Nacional tem um papel preponderante, uma nobre missão no conjunto das organizações do Governo Federal à valorização da chamada questão regional.

O Ministério da Integração Nacional é, sobretudo, o ministério do desenvolvimento regional. Integração nacional, nesse sentido, significa coesão social e econômica da base regional, e a redução das desigualdades regionais, nossa obsessão. No mesmo evento de Bruxelas em 2010, ao qual me referi anteriormente, o diretor do Departamento-Geral de Políticas Regionais da União Europeia, ao ser perguntado sobre quais eram os principais problemas da política regional do bloco, citou em alto e bom som a "coordenação de ações no território e a comunicação ao grande público do papel que cabe à política regional". Transportando para o caso brasileiro, se considerarmos a realidade nacional e a contribuição do Ministério da Integração Nacional, instituição com pouco mais de 10 anos de vida, portanto, com curta trajetória institucional, tais questões ganham escala e se caracterizam como desafios dantescos. É muito difícil desenvolver ações típicas de desenvolvimento regional sem o envolvimento de todas as áreas de governo. Sem coordenação, integração de políticas públicas nos territórios e parcerias concretas, não se produz resultado sustentável à redução das desigualdades regionais. Da mesma forma, sem um amplo consenso nacional que estabeleça prioridade ao combate das desigualdades regionais brasileiras, não creio em perspectivas reais de redução de nossas assimetrias, de resultados concretos. E, para tal, uma boa capacidade de comunicação ao grande público, à sociedade brasileira de maneira geral, sobre a importância e prioridade da matéria é sine qua non. O Ministério não tem essa capacidade de coordenação, aliás, não tem o mandato, arrisco a afirmar, para tal movimento. $\mathrm{Na}$ União Europeia, por exemplo, existe um grande Departamento, com um grande número de funcionários de todo o bloco (mais de 700 especialistas), com irrefutável qualificação, com mandato claro, trabalhando nesse sentido, e ainda assim com percalços e dificuldades pela complexidade da tarefa. Ou seja, precisamos, prioritariamente, melhorar nossas estruturas organizacionais para que elas tenham condições de responder ao desafio do desenvolvimento regional, à demanda de redução das nossas desigualdades regionais. Mas precisamos de uma decisão política que ofereça ao tema a prioridade indispensável que a ele deve ser estabelecida. Deve-se considerar, além disso, que a cultura brasileira é basicamente setorial e que temos muita dificuldade em convergir setores para problemas comuns, para territórios comuns, que sejam. O positivo neste momento é que cresce o consenso nos governos sobre a importância da questão regional, do olhar para o território, que se traduz no crescente número de iniciativas neste sentido.

O período pós-2010 nos coloca alguns desafios importantes para a política regional brasileira. A partir de agora, temos que implementar uma nova estratégia de política regional. Em 2003, fizemos algumas apostas territoriais, algumas escolhas no período que, assim considero, inaugurou a retomada da questão regional no Brasil, como, por exemplo, as Mesorregiões Diferenciadas (14 no total, dentre elas a Metade Sul do Rio Grande do Sul), a 
faixa de fronteira brasileira com os países da América do Sul, o semiárido, etc. Aliás, eu tive a oportunidade e o privilégio de ser o primeiro gerente dessa Mesorregião, a da Metade Sul do Rio Grande do Sul, e experimentei as dificuldades próprias da mudança do paradigma, da ação de "cima para baixo" para a ação articulada, da "consulta zero" ao "empoderamento" de atores, da capacitação de interlocutores para o novo paradigma como prioridade máxima, etc. Recordo-me da dificuldade que tivemos na gênese do processo para articular atores, para que desenvolvêssemos políticas integradas para a região, inclusive dentro do Governo do Estado, tanto quanto no caso do Governo Federal. Estou convencido de que não se faz política regional sem o envolvimento dos atores, sem comprometimento coletivo, e isso só se consegue com novas práticas, com um novo modelo de governança regional/territorial. Novas práticas como o diálogo com atores protagonistas do processo de desenvolvimento regional, por exemplo, algo extremamente complexo, mas que é uma das determinações que marcam o atual momento da gestão de políticas públicas. Por outro lado, não se pode deixar que fatores como a limitada capacidade de interlocução com atores regionais/locais impeçam o andamento e a implementação da política regional brasileira neste momento de mudanças. Se, por um lado, devemos apoiar todas as formas de diálogo, por outro não é razoável que se prejudique a evolução da ação regional, que urge velocidade e contundência por dificuldades próprias de processo tão sensível e inovador.

O pós-2010 nos desafia a produzir um olhar integral da política regional, para todo o território nacional. Tal mudança pode angariar novos apoios à política regional, inclusive apoio político, tendo, é claro, o cuidado de tratar desigualmente os desiguais. A estratégia que envolve a discussão de uma proposta de Fase II da PNDR é considerar o que, de fato, foi feito nesses últimos anos e, a partir das lições aprendidas, discutir amplamente o futuro da política, com amplos segmentos da sociedade brasileira.

Lançamos, neste sentido, um documento, uma "proposta para discussão", que está disponível no sítio do Ministério da Integração Nacional, denominado Política Nacional de Desenvolvimento Regional em dois tempos: A experiência apreendida e o olhar pós-2010. A primeira parte do documento resume o que construímos nos últimos oito anos de vigência da PNDR. A segunda parte apresenta uma proposta para o futuro que se debruça sobre os próximos passos da política regional brasileira.

I) O primeiro ponto, essencial, da proposta é tornar a PNDR uma política de Estado ela hoje é política de Governo. II) $\mathrm{O}$ segundo ponto, tão importante quanto, é a implementação do processo de descentralização da Política, visando modificar o processo de gestão da PNDR, atualmente sob amplo protagonismo do Ministério da Integração Nacional (MI). De acordo com um levantamento do Tribunal de Contas da União, no ano de 2008, foram investidos cerca de R\$ 23 bilhões por meio da PNDR, o que não é pouco dinheiro, sendo que R $\$ 14$ bilhões deste total, via Fundos Constitucionais, isto é, crédito à iniciativa privada, destinados às Regiões Norte, Nordeste e Centro-Oeste. A proposta da descentralização operacional da PNDR representa verdadeira desconcentração financeira da política regional, pois, a partir da criação do Fundo Nacional de Desenvolvimento Regional 
(FNDR), que faz parte da PEC da Reforma Tributária, serão criados Fundos Estaduais de Desenvolvimento Regional. Assim, cada Unidade da Federação deverá ter sua parcela do fundo nacional, compondo as dotações de fundos estaduais, que poderão receber contrapartidas próprias, potencializando as ações de redução das desigualdades regionais em consonância como Planos Estaduais de Desenvolvimento Regional. III) O terceiro ponto a ser destacado é o modelo de gestão, proposta que envolve múltiplos atores e novas instâncias participativas. Contempla:

- a estruturação de um Conselho Nacional de Desenvolvimento Regional, que deverá ser a instância máxima que discutirá as questões estratégicas relacionadas à política regional brasileira;

- a reestruturação da Câmara da Política de Desenvolvimento Regional, que deverá coordenar e organizar a ação dos órgãos de governo no território;

-a criação de um terceiro nível, que hoje inexiste, dos Conselhos Estaduais de Desenvolvimento Regional, para discutir as prioridades da questão regional no âmbito das Unidades da Federação, com objetivo de produzir uma interlocução entre o nacional e o local; e, por fim;

-o quarto nível de atuação reunirá os atores regionais, protagonistas locais e subregionais da questão que nos move, como o caso dos consórcios municipais, das agências subregionais de desenvolvimento, fóruns e demais estruturas de caráter regional associadas à política regional brasileira.

No que tange às oportunidades de cooperação internacional, mais especificamente à cooperação com a União Europeia, é importante recordar que, em 2006, foi realizado um evento para discutir teorias e conceitos do desenvolvimento regional no Brasil e na Europa. Na época, o então secretário de Políticas Regionais do Ministério da Integração Nacional, Antônio Carlos Galvão, tinha recém retornado de seu "doutorado-sanduíche", realizado na Universidade de Sussex, na Inglaterra. O colega elaborou um amplo estudo sobre a política regional europeia comparada e nos proporcionou uma série de contatos que foram fundamentais para o êxito do evento, que deu início a uma série de providências que acabaram culminando em acordo de cooperação com a Europa. O evento de 2006, o marco do processo de cooperação, reuniu os principais estudiosos brasileiros da questão regional e grandes representantes estrangeiros. A partir de então, começamos a discutir a possibilidade da elaboração de um Memorando de Entendimento entre Brasil e União Europeia. Dois anos após a realização do evento inicial, em 2008, foi assinado o Memorando de Entendimento em políticas regionais entre o Brasil, por meio do Ministério da Integração Nacional, e a Comissão Europeia, por meio do Departamento-Geral de Políticas Regionais, o DG-Regio. A celeridade do processo e a seriedade com que se construíram as bases da cooperação permitiram que a iniciativa fosse considerada exemplar e citada, por representantes europeus, como um modelo de cooperação em políticas regionais da UE com "terceiros países" (expressão usada para a articulação da UE com nações externas ao bloco europeu). 
A cooperação em andamento tem lastro e suporte importante das autoridades europeias, inclusive da Comissão de Desenvolvimento Regional do Parlamento Europeu. O Parlamento tem, inclusive, aportado recursos ao DG-Regio para financiamento da cooperação, com recursos alocados para duas das mais importantes ações estabelecidas como prioritárias no processo: intercâmbio de atores das políticas regionais do Brasil e da União Europeia e capacitação de agentes regionais para gestão de políticas públicas. Elaborou-se um plano trianual, referente ao período 2009-2011, algo como uma proposta "guarda-chuva", e, a cada exercício, se estabelece um plano de ação anual em que se definem, com detalhes, objetivos, ações e metas anuais. Essa programação é estabelecida pelo Ministério da Integração Nacional, em conjunto com o Departamento-Geral de Política Regional da União Europeia em evento anual, realizado por ocasião da Semana Europeia de Cidades e Regiões - o chamado Open Days. Excepcionalmente, em 2011, devido à mudança de governo, o planejamento será elaborado em uma oficina de trabalho que decidirá o plano anual para a cooperação. Prevê-se o detalhamento da programação, com prioridades a serem estabelecidas, que nos remetem a temas como o intercâmbio de atores territoriais, assistência técnica, elaboração conjunta de projetos-piloto, capacitação e outras ações que possam consolidar e expandir a cooperação em andamento. Participarão da oficina de planejamento agentes envolvidos no processo, bem como interlocutores de áreas prioritárias e gestores da cooperação de ambos os lados.

Por fim, vale ressaltar que, no período de 2008 a 2010, foram realizadas, dentre outras ações relevantes, duas rodadas de intercâmbios de gestores da política regional brasileira e da política regional europeia, em que experiências e práticas de ações regionais foram ampliadas - consolidando contatos de atores da política regional brasileira com parceiros da política regional europeia, com foco em diferentes arranjos produtivos locais. Foram treinados mais de 500 atores da política regional brasileira, envolvendo técnicos do MI, do Governo Federal e das regiões elegíveis pela PNDR. Dentre estes, um evento em Foz do Iguaçu, que priorizou a capacitação de atores vinculados às Mesorregiões Diferenciadas, que são espaços prioritários da política regional brasileira. Em outra rodada de capacitação, foram treinados atores dos diferentes ministérios setoriais debruçados sobre a questão regional/territorial, visando melhorar a capacidade de compreensão e gestão acerca da questão afeta à cooperação, com ganhos expressivos à PNDR, a partir do aumento da adesão e da compreensão institucional a respeito do objeto da cooperação. A registrar, ainda, a evolução da cooperação no âmbito da área de fronteira do Brasil com a União Europeia, entre o Amapá e a Guiana Francesa, com a utilização de recursos do Plano Operativo da Amazônia, o "PO Amazonie", da Comissão Europeia, com a finalidade de exercitar um processo de gestão conjunta por meio de projeto-piloto orientado à gestão dos parques de Cabo Orange e Oiapoque em ambos os lados da fronteira do Brasil com a UE.

Portanto, para o período 2011-2013, estão estabelecidas as grandes áreas de cooperação que serão objeto do workshop que se realiza em abril, em Brasília/DF. Além de apoio e assistência técnica para as áreas de informação, monitoramento e avaliação, há o 
interesse em avançar em segmentos de produção e elaboração de informação para tomada de decisão, em técnicas de monitoramento e avaliação para políticas regionais e continuidade ao processo de treinamento e capacitação para gestores regionais, além de reforço ao intercâmbio de atores regionais de ambos os lados da cooperação. Também existe a possibilidade de se elaborarem outros projetos conjuntos na área de fronteira do Brasil com a União Européia, que poderão ser ampliados, sobretudo levando-se em consideração os interesses mútuos de ampliação da cooperação a outros blocos, como o caso do Mercosul.

Para encerrar, gostaria de reiterar minha crença sobre o papel estratégico do Brasil no contexto do desenvolvimento do continente sul-americano. Acredito que o país tem vocação para ser protagonista da integração sul-americana. Cabe ao Brasil um papel de líder da cooperação no continente, pois creio que a América do Sul se fragiliza sem ações concretas de integração regional, razão pela qual rechaço qualquer crítica à atuação recente do país quanto a sinalizações concretas de apoio, inclusive financeiro, aos nossos vizinhos. O êxito brasileiro é o êxito da América do Sul, uma vez que temos, sim, um papel expressivo no continente, como locomotiva no aspecto econômico e geopolítico. Nesse sentido, a expansão da nossa cooperação com a União Europeia para os países parceiros do Mercosul me parece fundamental. 